
March 1935

\title{
AN ACCURATE EBULLIOSCOPIC METHOD FOR DETER- MINING THE MOLECULAR WEIGHTS OF NONVOLATILE PETROLEUM FRACTIONS ${ }^{1}$
}

\author{
By Beveridge J. Mair ${ }^{2}$
}

\begin{abstract}
Accurate molecular weights are an essential aid to the chemical investigation of the lubricating oil fraction of petroleum. A modified Cottrell boiling-point apparatus in conjunction with a differential thermoelement has been used to obtain precise values for the boiling-point elevation. The behavior of $n$-nonacosane, anthracene, triphenylmethane, and two oil samples in "isooctane", $n$-heptane, and benzene, and of biphenyl in benzene has been studied. The ebullioscopic constants or apparent molecular weights have been shown to be a linear function of the concentration. Accurate molecular weights are not possible if the customary methods of calculation are employed, no matter what the precision with which the boiling-point elevation is determined. Accurate molecular weights may be obtained if the value of the ebullioscopic constant at infinite dilution is first determined by extrapolation from measurements made over a sufficient range of concentrations. Using this infinite dilution value, the apparent molecular weight of the unknown is computed from observations over a range of concentrations and the molecular weight obtained by extrapolation to infinite dilution. Employing this method, the average value found for the molecular weight of triphenylmethane in "isooctane", $n$-heptane, and benzene was 243.4 compared with the theoretical value 244.14 and for biphenyl in benzene 153.7 compared with 154.08 .
\end{abstract}

\section{CONTENTS}

Page

II. Choice of method 346

III. Description of apparatus

1. Cottrell boilers

2. Heating unit

3. Potentiometer

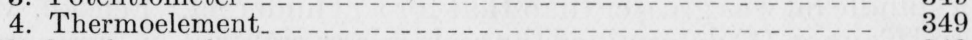

IV. Method and procedure 349

1. Constancy of heating current

2. Loss of solvent from the apparatus ...

3. Influence of light on the thermoelement____ 350

4. Procedure

5. Solvents $\ldots$

6. Solutes $\ldots$

V. Experimental results

VI. Conclusion $\ldots \ldots \ldots$

VII. Literature references

\footnotetext{
1 Financial assistance has been received from the research fund of the American Petroleum Institute. This work is part of Project 6, The Separation, Identification, and Determination of the Constituents of Petroleum.

2 Research associate representing the American Petroleum Institute,
} 


\section{INTRODUCTION}

An investigation of the chemical nature of the lubricating oil fraction of an Oklahoma petroleum has recently been undertaken at this Bureau. In the course of this investigation it will be necessary to know the empirical formulas of hydrocarbon fractions and of any hydrocarbons which may be isolated. The molecular weights of the hydrocarbons in the lubricating oil fraction are generally considered to lie in the range from 300 to 700 . To assign the correct number of carbon atoms to a hydrocarbon of molecular weight 700 requires that the molecular weight be known to within \pm 1 percent. The object of this work was therefore to develop a method by which molecular weights can be determined with an accuracy of \pm 1 percent.

\section{CHOICE OF METHOD}

Two methods only need be considered, namely, the cryoscopic and the ebullioscopic, since the vapor pressures of the fractions of interest in this work are too small to permit accurate vapor-density determinations. Most investigators of the molecular weights of nonvolatile petroleum fractions have used the cryoscopic method. Some of these investigators have used freezing-point measurements at one concentration to determine the molecular weight. Others, namely, Wilson and Wylde (1), ${ }^{3}$ Steed (2), Gullick (3), Devine (4), Fenske, McCluer, and Cannon (5) have found that the apparent molecular weight is a function of the concentration and have extrapolated to infinite dilution in an attempt to obtain the "true" molecular weight. If an oil shows a change in apparent molecular weight with change in concentration, it is evident that some value must be given preference to the others and an extrapolation to infinite dilution seems logical. Although such an extrapolation apparently gives the correct molecular weight in a few instances (Steed obtained excellent agreement between the infinite dilution value of the molecular weight of a gasoline determined cryoscopically in nitrobenzene and its molecular weight determined by the vapor-density method), there is plenty of evidence to indicate that it does not invariably give the correct result. Gullick (3) has shown that the molecular weights of some lubricating oils determined cryoscopically in nitrobenzene are not obtained correctly by extrapolation to infinite dilution. Among other obviously incorrect results he found that the infinite dilution value of the molecular weight for a spindle oil was greater than that for a cylinder oil. Fenske, McCluer, and Cannon (5) determined the molecular weigh ts of six pure compounds in cyclohexane. The results show that accurate molecular weights are frequently not obtained with the cryoscopic method even with extrapolation to infinite dilution.

There are two theoretical reasons why the cryoscopic method may give incorrect results even when a high degree of precision is used in the determination of the freezing-point lowering. One of these is that some component of the oil may form mixed crystals with the solvent. This is more likely to occur the more closely the chemical nature of the solvent resembles that of the solute. In this case extrapolation to infinite dilution will not give the true molecular weight.

${ }_{3}$ The figures given in parentheses here and elsewhere in the text correspond to the numbered references at the end of this paper. 
The other reason is that such large deviations from the ideal freezingpoint law may occur, even at very low concentrations, that incorrect results are obtained on extrapolation to infinite dilution. These large deviations from the ideal freezing-point law are more likely to occur the more dissimilar the chemical nature of the oil and solvent. Thus, with the cryoscopic method, if a solvent similar in chemical nature is chosen, mixed crystals may result; with one dissimilar in nature, large deviations from the ideal solution laws are possible. With the ebullioscopic method, the question of mixed crystals does not enter, and a solvent may be chosen which resembles the solute as closely as possible so that deviations from ideality are kept at a minimum.

Another practical consideration favors the boiling-point method. The solubility of hydrocarbon oils and waxes of high molecular weight in many solvents at the freezing point is limited, so that few solvents are available for selection. At the boiling point the solubility is much greater and a much greater number of solvents are available.

The boiling-point method is applicable only to fractions whose boiling points are at least $150^{\circ} \mathrm{C}$, and preferably $175^{\circ} \mathrm{C}$, higher than the solvent.

Although the ebullioscopic method possesses these theoretical and practical advantages it has been used comparatively little to determine the mean molecular weights of lubricating oils. This is probably because the ebullioscopic method has hitherto been considered less precise than the cryoscopic method. One of the difficulties encountered with the ebullioscopic method, namely, superheating, has been removed by the development of the Cottrell (6) boiler. A further difficulty with boiling-point measurements has been the control of the atmospheric pressure above the boiling liquid or the correction of the boilingpoint data to a standard atmospheric pressure. This difficulty has been obviated by Washburn and Read (7), who made simultaneous readings of the boiling points of two Cottrell boilers, one containing solution and the other pure solvent. This difficulty is also obviated in the apparatus of Menzies and Wright (8), in which a differential thermometer in a single Cottrell boiler is used.

Accordingly, the ebullioscopic method was chosen for further investigation and the present paper covers a detailed description of the apparatus and procedure developed, together with preliminary data on the use of three different solvents. The apparatus involves a number of improvements over that employed by the above-named investigators, and evidence is presented that the method is convenient, rapid, and capable of giving an accuracy of 1 percent.

\section{DESCRIPTION OF APPARATUS}

The apparatus consisted of (a) two vacuum-jacketed Cottrell boilers, one for solvent and one for solution, equipped for electrical heating; (b) a ten-junction differential thermoelement for measuring the boiling-point elevation; and (c) a special thermoelement potentiometer of high accuracy.

\section{COTTRELL BOILERS}

The Cottrell boilers were designed by M. M. Hicks-Bruun and were similar to those used by Washburn and Read (7) and Pearce and Hicks (9). One of these Cottrell boilers of a heat-resistant 


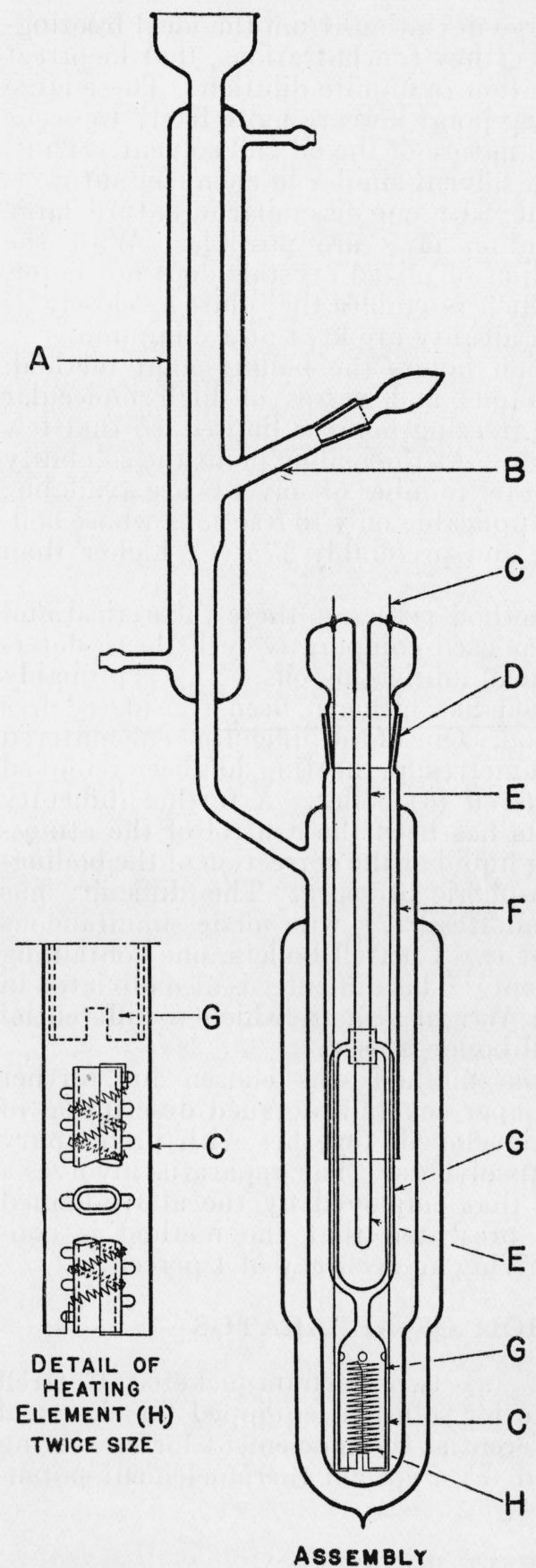

Figure 1.-One of the modified Cottrell boilers glass is shown schematically in figure 1. Through the wall of the condenser $(A)$ is sealed a side tube (B), fitted with a ground-glass stopper used for the introduction of liquid solutes. Solid solutes were added through the funnelshaped top of the condenser. Through the ground-glass stopper (D), heavy tungsten leads (C) were sealed which ran close to the bottom of the apparatus and to which was hard soldered the heating unit $(\mathrm{H})$. The pumping apparatus (G) was held by the tungsten leads and heating unit and was removable with the groundglass stopper. The thermoelement well (E), the lower portion of which was made of thin glass, was also supported by the ground-glass stopper. The thermoelement wells were filled with a nonvolatile, highly refined mineral oil. (F) is a glass sheath which serves to protect the thermoelement from the influence of cold liquid running from the condenser. When filled to slightly above the pumping bell, the apparatus contained approximately $30 \mathrm{ml}$ of liquid.

\section{HEATING UNIT}

The heating unit lowered below the bell of the pumping apparatus is shown in detail in the inset of figure 1 . The heating unit, made of no. 26 B. \& S. gage nichrome wire was first tightly coiled, then wound around a glass frame, inserted in the bell of the pumping apparatus, and hard-soldered to the tungsten leads. The glass frame consisted of a somewhat flattened glass tube to which were sealed glass knobs to prevent contact between the spirals of the heating coil.

The upper end of the wire was led out through the glass tube. The 
resistances of the heating units for the two boilers were made approximately equal, one being 19.0 and the other 18.9 ohms.

\section{POTENTIOMETER}

The potentiometer was designed by Brooks and Spinks (10) and constructed especially for use with the ten-junction copper-constantan thermoelement to determine accurately small temperature differences. In the usual instrument the unknown emf is balanced by an equal potential difference, obtained by changing the value of resistance between the two tap-off points on a circuit in which a current is maintained at a preassigned standard value. In this instrument, however, the unknown emf is balanced by an equal potential difference obtained by changing the value of current flowing through standard resistances. This change from the usual design made possible an instrument extraordinarily free from parasitic emf. Provision was also made in the instrument for detecting and eliminating parasitic emf in the galvanometer circuit.

The potentiometer was graduated to read directly in degrees centigrade and not in units of emf. The instrument has six ranges, namely, from $0^{\circ}$ to $0.1^{\circ}, 0.2^{\circ}, 0.5^{\circ}, 1^{\circ}, 2^{\circ}$, and $5^{\circ} \mathrm{C}$, respectively, each range subdivided into 100 divisions readable by estimation to 0.1 division. A description of the method of calibration of the potentiometer scale for use with the group of ten copper-constantan couples is given by Brooks and Spinks (10). Since the potentiometer was graduated to read directly in degrees rather than units of emf, provision for compensating for the variation of $\frac{d E}{d T}$ with $T$ was provided. In practice it was necessary only to set a dial (the bath temperature dial) at the boiling temperature of the solvent.

\section{THERMOELEMENT}

The ten-junction thermoelement was made from no. 30 B. \& S. gage constantan wire, tested for homogeneity, and from no. 40 B. \& S. gage copper wire. The junctions were soldered, using rosin as a flux, and insulated from each other with bakelite varnish. The thermoelement was calibrated by the heat division of this Bureau. Calibration is not essential, for no error would be introduced into the determination of molecular weights, since the apparatus is calibrated for each solvent with substances of known molecular weight. All that is necessary is that the relation of temperature to emf for the thermoelement remain constant throughout the experiments. The Cottrell boilers were placed close together so that as little as possible of the thermoelement was exposed. The thermoelement extended $22 \mathrm{~cm}$ into the wells and the distance between wells was $7 \mathrm{~cm}$.

\section{METHOD AND PROCEDURE}

\section{CONSTANCY OF HEATING CURRENT}

In any determination of molecular weights by the boiling-point method, the question as to what is the composition of the solution in contact with the temperance indicator arises. Solvent is absent from the solution both as vapor and as condensate on the walls of the vessel, and the concentration is not that calculated from the weights 
of solvent and solute introduced. The method employed in this instance to get around this difficulty is to supply energy at a constant rate to the apparatus so that the amount of solvent absent from the solution remains constant. The apparatus can then be calibrated for each solvent with substances of known molecular weight.

Direct current from lead storage batteries at $70 \mathrm{v}$ flowed through the Cottrell heaters connected in series with one another and in series with a variable external resistance and an ammeter. The current necessary for steady operation was noted for each solvent and in subsequent work the ammeter was brought to the same reading within $\pm 0.02 \mathrm{amp}$. The effect of variation in current on the boiling-point elevation was observed in a few cases. For a solution of $1.3116 \mathrm{~g}$ of triphenylmethane in $19.883 \mathrm{~g}$ of $n$-heptane, $\Delta T$ equalled $1.020^{\circ}$ and $1.036^{\circ} \mathrm{C}$ for currents of 1.35 and $1.55 \mathrm{amp}$, respectively. If a precision of 0.2 percent is required, it is necessary to keep the current constant within $\pm 0.025 \mathrm{amp}$. The currents used were $1.40 \mathrm{amp}$ for benzene and $1.45 \mathrm{amp}$ for $n$-heptane and "isooctane."

\section{LOSS OF SOLVENT FROM THE APPARATUS}

In order to prevent loss of solvent, the ground-glass stoppers were tightly sealed by flowing a small quantity of lubricant into the upper rim of the ground-glass joint. Tetraethylene glycol citrate resin was used when benzene was the solvent employed. At the temperature of boiling heptane and "isooctane", this substance is rather fluid and ethylene glycol citrate resin was used instead. These resins, obtained from T. P. Sager (11), are insoluble in aromatic and aliphatic hydrocarbons.

\section{INFLUENCE OF LIGHT ON THE THERIMOELEMENT}

The Cottrell units with thermoelement were placed on a table about 2 feet from a window, one unit being closer to the window than the other. Apparently, unequal radiation fell on the two legs of the thermoelement or else their surfaces were not identical and adsorbed radiation in a different manner. The observations reported in table 1 , made on a cloudy day with pure benzene in both boilers, show the effect of light.

For this reason the observations were always made with the shades entirely down, and with both Cottrell boilers covered with black cloth.

TABLE 1.-Data showing the influence of light on the thermoelement

\begin{tabular}{|c|c|c|c|c|c|c|c|}
\hline $\begin{array}{c}\text { Cottrell unit with } \\
\text { the higher tem- } \\
\text { perature }\end{array}$ & Time & $\Delta T$ & $\begin{array}{l}\text { Position of } \\
\text { shades }\end{array}$ & $\begin{array}{c}\text { Cottrell unit with } \\
\text { the higher tem- } \\
\text { perature }\end{array}$ & Time & $\Delta T$ & $\begin{array}{l}\text { Position of } \\
\text { shades }\end{array}$ \\
\hline $\begin{array}{l}\mathrm{A} \\
\mathrm{A} \\
\mathrm{B} \\
\mathrm{B}\end{array}$ & $\begin{array}{l}2: 12 \\
2: 15 \\
2: 16 \\
2: 20\end{array}$ & $\begin{array}{r}0.0005 \\
.0012 \\
.0065 \\
.0060\end{array}$ & $\begin{array}{l}\text { Down. } \\
\text { Do. } \\
\text { Half-way up. } \\
\text { Do. }\end{array}$ & $\begin{array}{l}\mathrm{B} \\
\mathrm{B} \\
\mathrm{A}\end{array}$ & $\begin{array}{l}2: 23 \\
2: 26 \\
2: 27 \\
2: 29\end{array}$ & $\begin{array}{l}.0149 \\
.0155 \\
.0005 \\
.0007\end{array}$ & $\begin{array}{l}\text { Up. } \\
\text { Do. } \\
\text { Down. } \\
\text { Do. }\end{array}$ \\
\hline
\end{tabular}




\section{PROCEDURE}

A known weight of solvent was introduced into one of the boilers by means of a weighing pipette with a long side arm, ${ }^{4}$ inserted several inches into the apparatus to minimize loss by volatilization. Into the other boiler approximately the same quantity $(30 \mathrm{ml})$ was added from a graduated cylinder. The ground-glass stoppers were inserted, lubricant was flowed around their rims, and the thermoelement inserted in its well, the room darkened and boiling started. After about 20 minutes, readings of the temperature difference between the two Cottrell boilers were started. Even with pure solvent in both boilers a difference of temperature occasionally as great as $0.008^{\circ}$, but usually from $0.002^{\circ}$ to $0.004^{\circ} \mathrm{C}$ was observed. The readings of this difference were generally constant to within $\pm 0.0005^{\circ}$ $\mathrm{C}$, although sometimes variations amounting to $\pm 0.0010^{\circ} \mathrm{C}$ were observed. After this difference in temperature had been determined a weighed portion of solute was added. The solid solutes were added in the form of pills. The liquid solutes were added from a weighing pipette with a long side arm, care being taken that all the solute fell into the central condenser tube. The heating current was temporarily increased in order to raise the reflux level and wash all the solute into the lower part of the boiler. The heating current was then returned to its predetermined value, and after about 15 minutes, readings of the temperature difference were begun. About 5 or 6 readings were taken at 2 to 3 minute intervals. These readings, usually constant to within $\pm 0.0005^{\circ} \mathrm{C}$, were averaged and corrected for the difference observed when pure solvent was in both boilers.

\section{SOLVENTS}

Three hydrocarbons, benzene, $n$-heptane, and "isooctane" $(2,2,4$ trimethylpentane) were used as solvents. These were chosen for variety of type and because they are available commercially in reasonably pure condition. Since each solvent is calibrated, exceptional purity does not seem necessary, provided very volatile constituents are absent. The benzene, which conformed to American Chemical Society specifications for reagent benzene, was distilled once through a very efficient fractionating column and the first and last fifths were rejected. The $n$-heptane used was obtained from the California Chemical Co., and had the following constants: Freezing point $-90.7^{\circ} \mathrm{C}$, boiling point $98.4^{\circ} \mathrm{C}, D_{4}^{20}=0.6837, n_{\mathrm{D}}^{20}=1.3878$. The "isooctane", a mixture of commercial samples, had a refractive index $n_{\mathrm{p}}^{25}=1.3890$ and froze over a range of $0.5^{\circ} \mathrm{C}$.

\section{SOLUTES}

The hydrocarbons used as solutes, n-nonacosane, anthracene, triphenylmethane, and biphenyl, also were chosen with a view to variety of type and availability. The $n$-nonacosane was a sample of exceptional purity, prepared by Doctor K. S. Markley, Bureau of Plant Industry, U. S. Department of Agriculture, from Rome Beauty apple cuticle. Certain constants for this material obtained by Markley are compared in table 2 with those obtained by Piper, et al. (12) for pure synthetic $n$-nonacosane.

${ }^{4}$ Similar to that shown by Findlay, Practical Physical Chemistry, page 126, Longmans, Green and Co. $1925)$. 
TABLE 2.-Constants of n-nonacosane

\begin{tabular}{|c|c|c|}
\hline & \multicolumn{2}{|c|}{$\begin{array}{l}\text { Temperatures obtained } \\
\text { by- }\end{array}$} \\
\hline & Markley & Piper, et al. \\
\hline First transition on heating & ${ }^{\circ} \mathrm{C}$ & ${ }^{\circ} \mathrm{C}$ \\
\hline $\begin{array}{l}\text { Second transition on heating - } \\
\text { Melting point }\end{array}$ & $\begin{array}{r}62.7 \\
63.5-63.7\end{array}$ & $63.4-63.6$ \\
\hline Setting point & $63.1-62.9$ & 63. 2 \\
\hline First transition on cooling & 60.2 & \\
\hline Second transition on cooling........ & 55.2 & 56.0 \\
\hline
\end{tabular}

Doctor Sterling B. Hendricks, Division of Fertilizer Investigation, Bureau of Chemistry and Soils, submitted the above specimen to $\mathrm{X}$-ray examination with the following results: Using a pressed-onglass specimen and $\mathrm{Cr}-\mathrm{K}$ radiation, a spacing of $d_{(001)}=39.00 \pm .20 \mathrm{~A}$ was obtained. (Compare Piper et al., $d_{(001)}=38.68$ with an accuracy of 1 percent.) The original plate showed eleven orders of reflection with little diminution of intensity toward the end of the plate. The dimensions of the plate would not permit the observation of orders beyond the eleventh. Eight or more orders of reflection is one of the criteria of purity listed by Piper et al.

Anthracene from Kahlbaum was purified by the method of Winterstein and Schön (13) who obtained pure anthracene by removing the colored compounds from technical anthracene by adsorbing them on active alumina from a benzene solution. The same method was employed here, both active alumina and silica gel being used. The silica gel seemed quite as effective as the alumina in removing color. The anthracene was then crystallized once from benzene and the solvent removed by heating in vacuum. The anthracene thus obtained melted at $216^{\circ} \mathrm{C}$.

Eastman's triphenylmethane (catalog no. 833), melting at $92.0^{\circ} \mathrm{C}$, was crystallized once from alcohol. This purified material melted slightly higher, at $92.5^{\circ} \mathrm{C}$.

The biphenyl melted at $67^{\circ} \mathrm{C}$, compared with $69^{\circ} \mathrm{C}$ for a sample of Eastman's (catalog no. 721). These melting points were made by the capillary tube method and are not reliable to better than $\pm 1^{\circ} \mathrm{C}$.

With the exception of the $n$-nonacosane, which was very pure, no claim is made for exceptional purity for these compounds. The biphenyl was less pure than the others. It was used only in preliminary experiments with benzene as a solvent, since its vapor pressure is sufficiently high at $100^{\circ} \mathrm{C}(4.35 \mathrm{~mm})$ to cause appreciable errors, with the higher boiling solvents.

Two samples of oil from the same Oklahoma crude were investigated. One of these was a "water white" sulphur-free oil obtained by filtration through silica gel; the other a highly colored sulphur dioxide extract. Certain physical characteristics of these oils are recorded in table 3 . These samples correspond in physical properties to a "paraffin" base oil and to a "naphthene" base oil. 
TABLE 3.-Certain physical characteristics of oil samples

\begin{tabular}{|c|c|c|c|c|c|}
\hline \multirow{2}{*}{ Sample } & \multirow{2}{*}{$\mid \begin{array}{c}\text { Refrac- } \\
\text { tive index } \\
n_{\mathrm{D}}^{25}\end{array}$} & \multicolumn{2}{|c|}{ Density at- } & \multicolumn{2}{|c|}{$\begin{array}{l}\text { Kinematic viscosity } \\
\text { at- }\end{array}$} \\
\hline & & $150^{\circ} \mathrm{F}$ & $210^{\circ} \mathrm{F}$ & $150^{\circ} \mathrm{F}$ & $210^{\circ} \mathrm{F}$ \\
\hline $\begin{array}{l}\text { Silica gel filtrate "water white" } \\
\text { Sulphur dioxide extract "highly colored"- }\end{array}$ & $\begin{array}{l}1.4674 \\
1.5485\end{array}$ & $\begin{array}{c}\mathrm{g} / \mathrm{ml} \\
0.817 \\
.976\end{array}$ & $\begin{array}{l}\mathrm{g} / \mathrm{ml} \\
0.794 \\
.951\end{array}$ & $\begin{array}{c}\text { Stokes } \\
0.0775 \\
.2006\end{array}$ & $\begin{array}{l}\text { Stokes } \\
0.0367 \\
.0780\end{array}$ \\
\hline
\end{tabular}

\section{EXPERIMENTAL RESULTS}

The results of the calibration experiments for the three solvents, using as calibrating solutes $n$-nonacosane and anthracene, are shown in figure 2 , in which the ebullioscopic constant $K=\frac{\Delta T}{x_{1}}$ (where $\Delta T$ is the boiling-point elevation and $x_{1}$ the mole fraction of solute) is shown as a function of the concentration in mole percent. It is apparent that $K$ is far from being independent of the concentration, and furthermore that $K$ at any finite concentration for any solvent also depends on the chemical nature of the solute. A lineal relationship seems to exist between $K$ for each solute and the concentration. The values for $K$ for the two solutes approach each other at low concentrations. It is seen that the data are reproduced within the experimental error if the lines for the two solutes are extrapolated to give the same value for $K$ at infinite dilution. It is apparent that one method of computing molecular weights, i. e., determination of the constant $K$ for the solvent by the use of a solute of known molecular weight at a finite concentration, and the use of this constant to compute the molecular weight of the unknown from observations at approximately the same concentration may lead to gross errors. This method of computation when used to calculate the molecular weight of anthracene from the constant $K$ for $n$-nonacosane at 1.2 mole percent in heptane, "isooctane", and benzene, gives results higher than the theoretical by $4.8,4.2$, and 1.8 percent, respectively. The only method of calculation, which will lead to the theoretical molecular weight of anthracene, is a computation of the apparent molecular weights of anthracene at various concentrations from the infinite dilution value of $K$ (from $n$-nonacosane), and extrapolating to infinite dilution these apparent molecular weights as a function of concentration. Obviously the molecular weight of $n$-nonacosane may be obtained in a similar manner from the value of $K$ for anthracene at infinite dilution.

The precision attained in these calibration experiments, and the values obtained for $K$ by extrapolating lines through the data for $n$ nonacosane and anthracene to a common point are shown in table 4. 


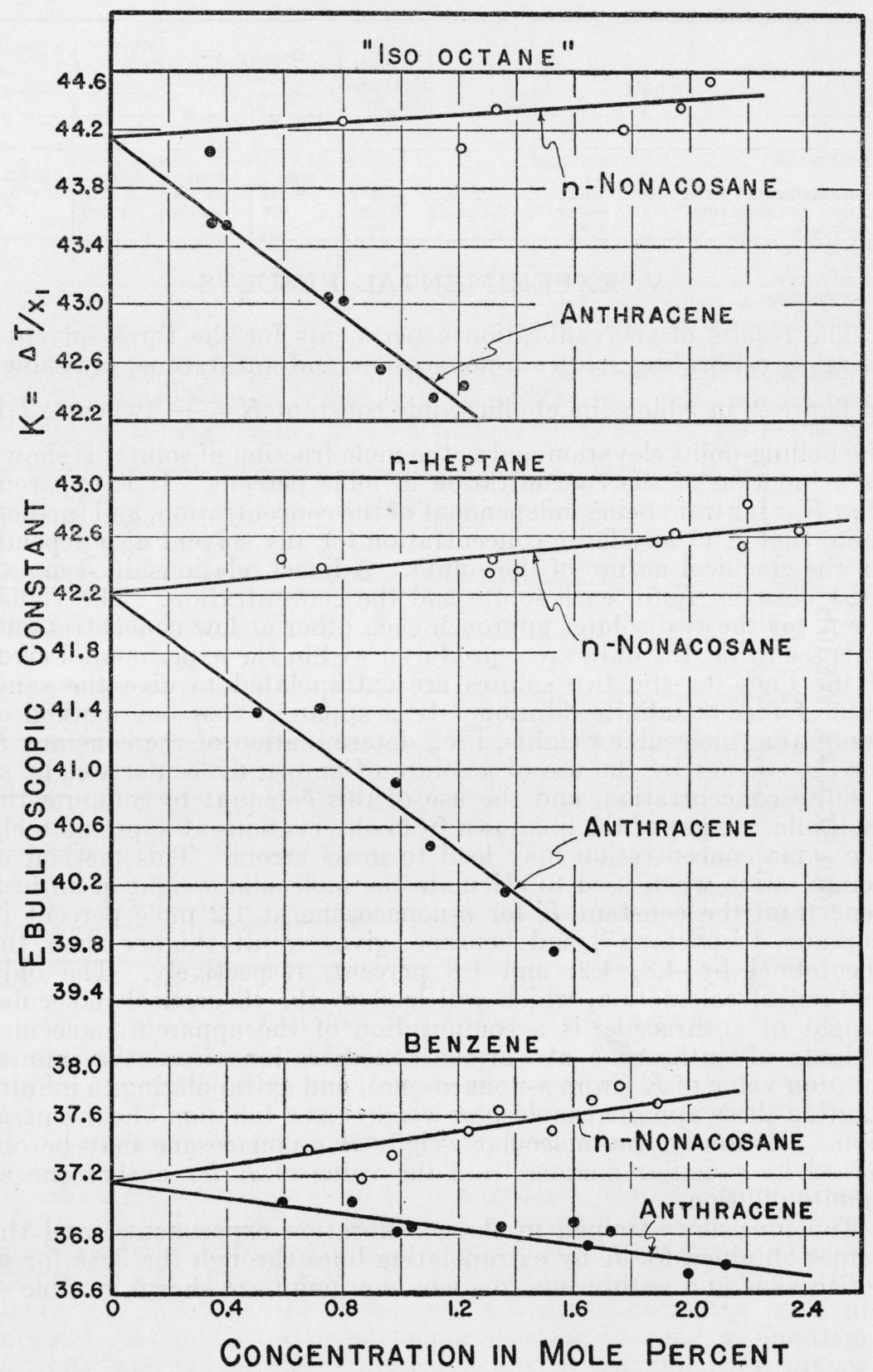

Figure 2.-Ebullioscopic constants $K=\frac{\Delta T}{x_{1}}$ as a function of concentration in mole percent for three solvents, "isooctane", n-heptane, and benzene.

$\bigcirc$ and represent values for $n$-nonacosane and anthracene, respectively. 
TABLE 4.-Summary of calibration experiments

\begin{tabular}{|c|c|c|c|}
\hline Solute & Solvent & $\begin{array}{c}\text { Maximum deviation of values from } \\
\text { extrapolation line }\end{array}$ & $\begin{array}{c}K=\frac{\Delta T}{x_{1}} \\
\operatorname{Lim} . x_{1} \doteq 0\end{array}$ \\
\hline Anthracene & "Isooctane".... & $\begin{array}{l}\text { Percent } \\
\text { one value at low concentration off }+1\end{array}$ & \\
\hline$n$-nonacosane... & -...-do_...... & $\begin{array}{l}\text { all otners within } \pm 0.15 \\
\pm 0.55\end{array}$ & 44. 14 \\
\hline $\begin{array}{l}\text { Anthracene } \\
n \text {-nonacosane...-. }\end{array}$ & 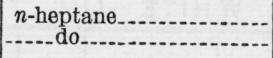 & \begin{tabular}{|l} 
\pm .65 \\
\pm .45
\end{tabular} & 42.20 \\
\hline $\begin{array}{l}\text { Anthracene..... } \\
n \text {-nonacosane }\end{array}$ & Benzene & \begin{tabular}{|l} 
\pm .38 \\
\pm .67
\end{tabular} & 37.16 \\
\hline
\end{tabular}

As a further check on the validity of this method of calculation, and on the accuracy with which the infinite dilution values of $K$ for all three solvents had been obtained, experiments with biphenyl in

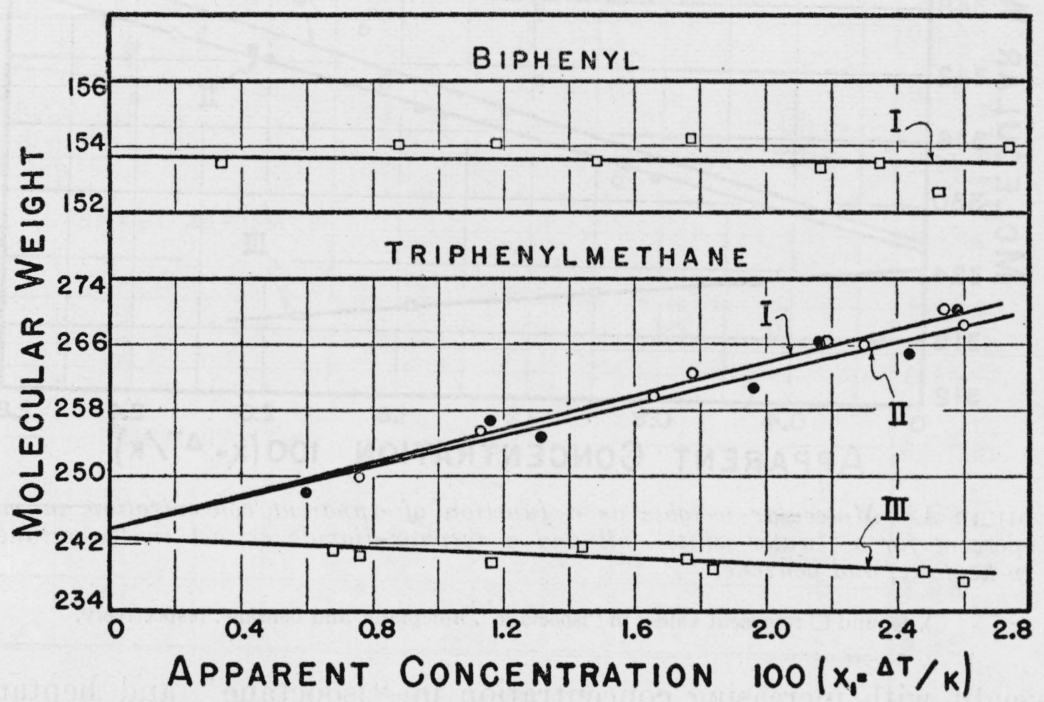

FIGURE 3.-Molecular weights as a function of apparent concentration in mole percent for biphenyl in benzene and triphenylmethane in "isooctane", n-heptane,
and benzene.

$\bigcirc$, and $\square$ represent values in "isooctane", $n$-heptane and benzene, respectively.

benzene, and triphenylmethane in all three solvents were made. The results of these experiments are shown in figure 3. Biphenyl in benzene shows very little if any change in apparent molecular weight with change in concentration, and the data lead to the value 153.7, in close agreement with the theoretical value 154.08. Triphenylmethane in benzene shows a small decrease in apparent molecular weight with increase in concentration, while in heptane and "isooctane" there are marked increases in apparent molecular weight with increase in concentration. By separate extrapolation to infinite dilution of the values obtained in benzene, "isooctane", and heptane, the values $242.6,243.6$, and 244.1 , respectively, are obtained in close agreement with the theoretical value 244.1. 
In figure 4 are shown the apparent molecular weights of the two oil samples as functions of concentration in all three solvents. The "water white" oil shows no change in apparent molecular weight with change in concentration in any of the three solvents. It is interesting to note that the sulphur dioxide extract behaves similarly to triphenylmethane and shows a marked increase in apparent molecular

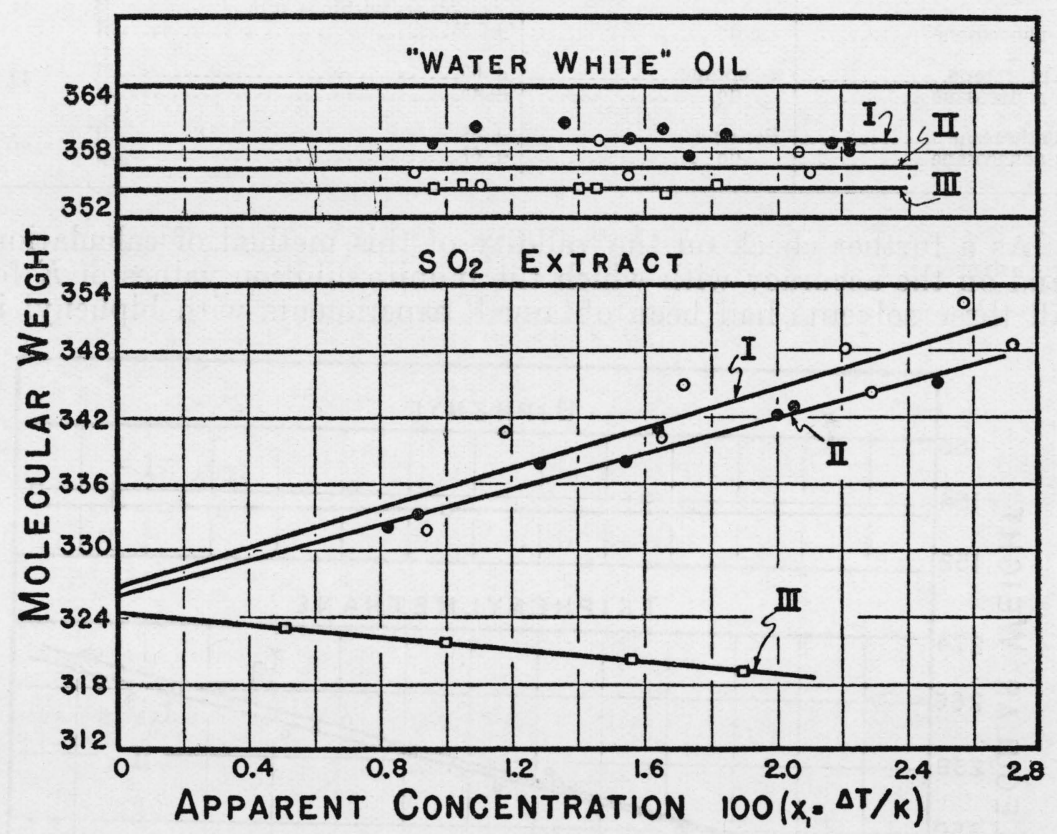

FigURE 4.-Molecular weights as a function of apparent concentration in mole percent for a "water white" oil and a sulphur-dioxide extract in "isooctane", n-heptane, and benzene.

$\bigcirc$, and $\square$ represent values in "isooctane", $n$-heptane, and benzene, respectively.

weight with increasing concentration in "isooctane" and heptane, and a slight decrease in benzene.

\section{CONCLUSION}

In table 5 is given a summary of the molecular-weight data. These data obtained with pure hydrocarbons representative of the most divergent types in petroleum indicate that extrapolation to infinite dilution gives correct molecular weights within 1 percent. In cases where very high deviations from ideal solution laws occur, it may not always be possible to make precise measurements at sufficiently low concentrations to permit extrapolation to the true molecular weight with the desired accuracy. Such cases seem very unlikely except when nonhydrocarbons are used as solvents. 
TABLE 5.-Summary of molecular weight data

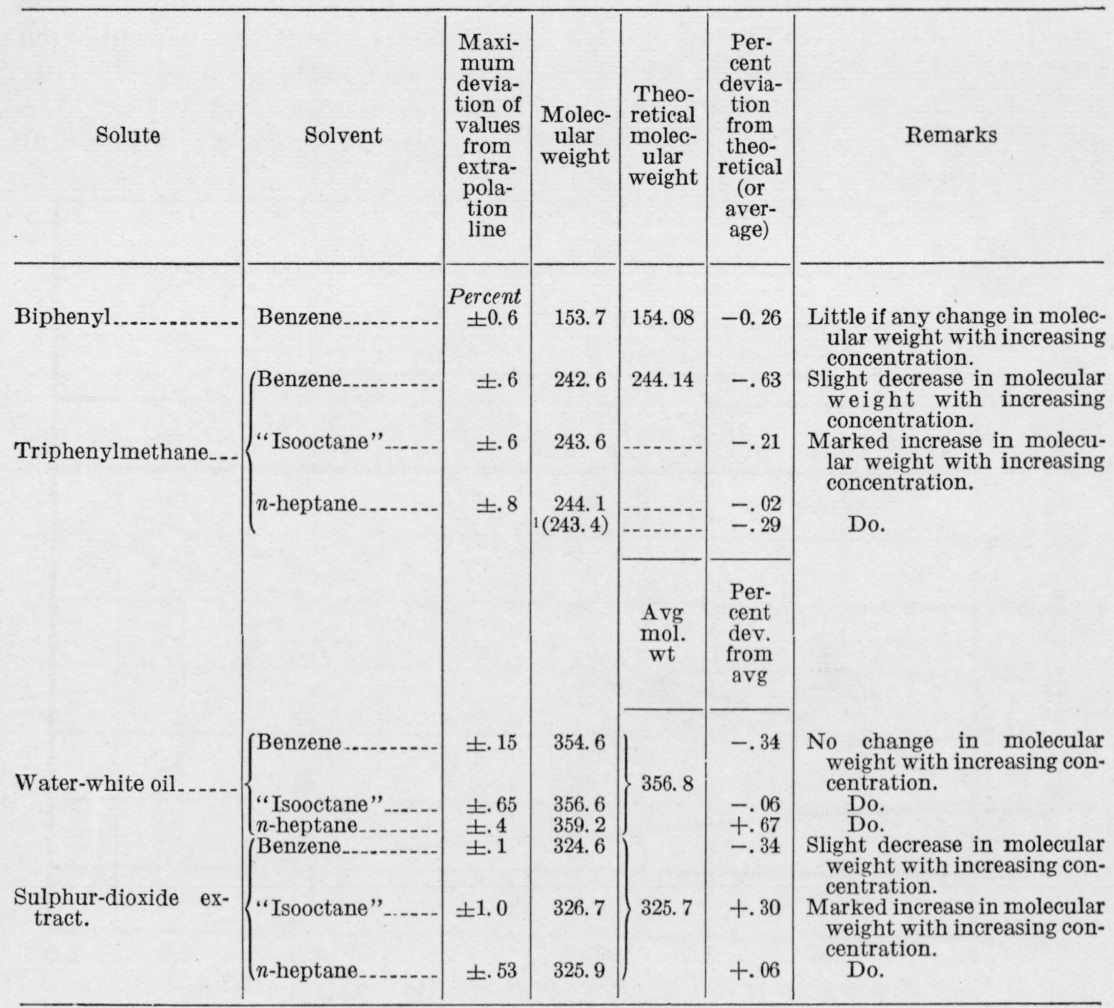

${ }^{1}$ Average in 3 solvents.

\section{LITERATURE REFERENCES}

(1) R. E. Wilson and E. Wylde. Ind. Eng. Chem. 15, 801 (1923).

(2) A. H. Steed. J. Inst. Petroleum Tech. 16, 799 (1930).

(3) N. G. Gullick. J. Inst. Petroleum Tech. 17, 541-71 (1931).

(4) J. M. Devine. Univ. Oklahoma Bull. 9, 131-7 (1929).

(5) M. R. Fenske, W. B. McCluer, and M. R. Cannon, Ind. Eng. Chem., 26, 976 (1934).

(6) F. G. Cottrell. J. Am. Chem. Soc. 41, 721-729 (1919).

(7) E. W. Washburn and J. W. Read. J. Am. Chem. Soc. 41, 729-741 (1919).

(8) A. W. C. Menzies and S. L. Wright. J. Am. Chem. Soc. 43, 2314 (1921).

(9) J. N. Pearce and M. M. Hicks. J. Phys. Chem. 30, 1678 (1926).

(10) H. B. Brooks and A. W. Spinks. BS J. Research 9, 781-798 (1932) RP 506.

(11) T. P. Sager. Ind. Eng. Chem., Anal. Ed. 4, 388 (1932).

(12) S. H. Piper, A. C. Chibnall, S. J. Hopkins, A. Pollard, J. A. B. Smith, and E. F. Williams. Biochem. J. 25, 2085 (1931).

(13) A. Winterstein and K. Schön. Naturwissenschaften 22, 237 (1934).

Washington, November 13, 1934. 